\title{
Sulphasalazine in ankylosing spondylitis: a double blind controlled study in 60 patients
}

\author{
MAXIME DOUGADOS, PATRICK BOUMIER, BERNARD AMOR
}

\begin{abstract}
Sulphasalazine has been reported to be effective in ankylosing spondylitis with peripheral arthritis, but its efficacy in spondylitis is unknown. Thus 60 patients with active ankylosing spondylitis without peripheral arthritis or gastrointestinal symptoms were randomly allocated to one of two therapeutic groups. One group received $2 \mathrm{~g}$ sulphasalazine daily for six months and the other a placebo. Thirteen patients (six given placebo and seven given sulphasalazine) dropped out of the trial and were considered to be treatment failures. After six months' follow up efficacy was rated as good or very good by 15 of the 30 patients given sulphasalazine and by only six of the 30 given placebo $(p<0.02)$. Furthermore, in the patients given sulphasalazine the daily consumption of non-steroidal anti-inflammatory drugs, functional index, and plasma IgG concentrations had fallen significantly.

These data suggest that sulphasalazine may be a safe and effective treatment for spondylitis in ankylosing spondylitis.
\end{abstract}

\section{Introduction}

Sulphasalazine has become the most widely used treatment for inflammatory diseases of the intestine and colon, ${ }^{1}$ and two studies have re-emphasised its value in rheumatoid arthritis. ${ }^{23} \mathrm{We}$ recently reported the benefits of such treatment in peripheral arthritis in patients with seronegative spondyloarthropathies without associated intestinal disease. ${ }^{4}$ By contrast, the usefulness of sulphasalazine in axial forms of ankylosing spondylitis has never been shown. Intestinal microbial infection has been incriminated in the pathogenesis of active exacerbations of this condition, ${ }^{5}$ and macro-

Clinique de Rhumatologie, Hôpital Cochin, 75674 Paris Cedex 14, France MAXIME DOUGADOS, MD, ancien chef de clinique assistant des hôpitaux PATRICK BOUMIER, MD, chef de clinique assistant des hôpitaux BERNARD AMOR, MD, professor of rheumatology

Correspondence to: Dr Dougados. scopic and microscopic abnormalities of the ileocolonic mucosa have been reported, ${ }^{67}$ suggesting a link between rheumatic disease and subclinical inflammation of the digestive mucosa. We undertook a therapeutic trial aimed at defining the value of sulphasalazine as basic treatment in axial forms of ankylosing spondylitis.

\section{Patients and methods}

Sixty patients fulfilling the New York criteria for the diagnosis of ankylosing spondylitis were included in the trial. ${ }^{8} \mathrm{~A}$ family history or the presence of minimal localised lesions of cutaneous psoriasis, or both, in eight of them was not considered to be a criterion for exclusion. None of the patients had symptoms suggestive of inflammatory enterocolonic disease. None was suffering from peripheral arthritis, but all required daily administration of non-steroidal anti-inflammatory drugs. To confirm that these drugs were necessary and to define the minimum dose needed to ensure the patient's comfort we asked each patient, at the selection visit, to decrease or even stop this treatment. Only those patients still requiring daily use of these drugs at the time of the inclusion visit (two weeks after the selection visit) were finally included in the trial.

We chose to use a double blind, placebo controlled trial. The randomisation list was in blocks of six. After confirming that the patient fulfilled the criteria defined above, and after he had given his informed consent, we supplied the study drug in numerical order. In addition to taking his current dose of non-steroidal anti-inflammatory drugs each patient took four tablets a day of either sulphasalazine (corresponding to $2 \mathrm{~g}$ ) or placebo for six months. Placebo and sulphasalazine (in the form of enteric coated tablets (Salazopyrine EN, Laboratoires Pharmacia, France)) were indistinguishable in terms of shape, colour, and taste. Patients and investigators were both unaware of the meaning of the randomisation code until the last patient had completed the trial. Each patient was seen by the same investigator, always in the morning, after one, three, and six months.

\section{CRITERIA OF EFFICACY}

Seven criteria were used to assess the efficacy of the treatment, although we considered the first two criteria to be the most important

Overall assessment at the end of the trial-At the end of the trial patients rated the efficacy of their treatment as nil, moderate, good, or very good. Nil and moderate efficacy were taken as indicating therapeutic failure.

Changes in daily dosage of non-steroidal anti-inflammatory drugs-The patients used various non-steroidal anti-inflammatory drugs of different therapeutic groups. To standardise this variable an equivalent score for 
different dosages of these drugs was drawn up on the basis of the opinion of 40 rheumatologists. A score of 10 was assigned to a daily dose of $100 \mathrm{mg}$ indomethacin, $30 \mathrm{mg}$ piroxicam, $125 \mathrm{mg}$ diclofenac, $300 \mathrm{mg}$ flurbiprofen, $1400 \mathrm{mg}$ ibuprofen, $1100 \mathrm{mg}$ naproxen sodium, $1000 \mathrm{mg}$ naproxen, $300 \mathrm{mg}$ phenylbutazone, $1200 \mathrm{mg}$ pirprofen, $900 \mathrm{mg}$ fenbufen, $200 \mathrm{mg}$ ketoprofen, $800 \mathrm{mg}$ tiaprofenic acid, $4000 \mathrm{mg}$ aspirin, $440 \mathrm{mg}$ bumazidone calcium, $200 \mathrm{mg}$ isoxicam, and $400 \mathrm{mg}$ sulindac. Thus, for example, a patient requiring $75 \mathrm{mg}$ indomethacin and $2 \mathrm{~g}$ aspirin daily was given a score of $12 \cdot 5$.

Severity of pain was evaluated by (1) using a visual analogue scale $100 \mathrm{~mm}$ long and (2) scoring for the presence of pain on movement or tenderness over 22 joint sites (on movement of right and left chondrosternal, anterior and lateral pressure on thorax, and right and left heel, flexion of right and left hip, flexion-abduction of right and left hip and right and left buttock, right and left rotation of cervical spine, flexion and extension of cervical spine, right and left rotation of dorsolumbar spine, and flexion and extension of lumbar spine). Patients were given a score of 0 if they did not have any pain, 1 if they described pain, 2 if in addition they grimaced, and 3 if there was also a withdrawal movement. The sum of the scores obtained for each joint was recorded.

The degree of inflammation was assessed by (1) the number of times the patient woke at night because of pain and (2) the latent period before the resolution of early morning stiffness (in minutes).

Functional impairment was estimated using a functional index. For this the investigating clinician provided the patient with a list of 30 questions corresponding to everyday gestures: "Can you: put on your shoes, lace your shoes, pull on trousers or underwear, pull on a jacket or shirt, pull on a pullover, get into or out of a bathtub, remain seated to eat, walk on your heels, remain standing for 10 minutes, walk, go up one flight of stairs, go down one flight of stairs, run, sit down, get up from a chair, get into a car, get out of a car, bend over to pick up an object, crouch, turn your head, bend your head, lie down, turn in bed, get out of bed, sleep on your back, sleep on your stomach, do your job or housework, watch television, cough or sneeze, breathe deeply?" A score of 0 was given if the action could be accomplished without difficulty, 1 if it was possible but difficult, and 2 if it was impossible. A therapeutic trial aimed at validating such articular and functional indexes in the assessment of efficacy of non-steroidal anti-inflammatory drugs in ankylosing spondylitis has been undertaken (Dougados $e t$ al, unpublished findings).

foint mobility was assessed on the basis of (1) Schober's test; (2) the distance between the patient's hand and the ground when the patient, standing, flexed his trunk forwards without bending his knees; and (3) chest expansion. The sum of three consecutive measurements was recorded.

Results of blood analysis-At each visit blood samples were drawn and analysed for the erythrocyte sedimentation rate, plasma haemoglobin concentration, platelet count, and serum immunoglobulin concentrations.

\section{STATISTICAL ANALYSIS}

Statistical analyses were done to assess the effects of sulphasalazine on all patients who entered the study and to assess improvement in those patients who continued treatment until the end of the study. Owing to the nonnormal distributions of many of the variables of response statistical analyses were made with non-parametric tests. Changes in the variables between the start and end of the trial by treatment group were compared with the nonparametric Mann-Whitney U test. The improvement within each group was tested by Wilcoxon's test. The threshold of significance adopted was $5 \%$ (one tailed).

\section{Results}

Table I summarises the characteristics of the patients at the start of the trial. There was no significant difference between the two groups in the demographic data or the clinical and laboratory variables measured. Thirteen of the 60 patients dropped out of the trial; table II shows the reasons for this.

Overall assessment of treatment-The overall efficacy of treatment was assessed by all patients included in the trial; the 13 patients who had had to stop treatment were taken as therapeutic failures regardless of the reason for stopping treatment. Using this method, treatment was considered to be effective by half of the patients taking sulphasalazine compared with one fifth of those taking placebo $(p<0 \cdot 02)$ (table III).

Detailed analysis of response to treatment - This analysis was undertaken in the 47 patients who completed the trial. Table IV shows the changes that had occurred in each variable by the end of the trial. Sulphasalazine resulted in a significant reduction in the daily dosage of non-steroidal anti-inflammatory drugs needed by the patients $(p<0 \cdot 05)$. Many other variables showed greater improvement in the patients receiving sulphasalazine than in those receiving placebo, but only the changes in functional index and serum IgG concentra- $\underline{-}$ tions were significantly different between the two groups. Significant improvements occurred in eight variables within the group receiving sulphasalazine (score for daily dose of non-steroidal anti-inflammatory $\varrho$ drugs, pain, joint index, functional index, erythrocyte sedimentation rate, $\subseteq$ plasma IgG and IgM concentrations, and hand-ground distance) compared $\widehat{\widehat{O}}$ with only two within the group receiving placebo (chest expansion and $\overline{\bar{F}}$ erythrocyte sedimentation rate) (table IV).

2 TABLE 1-Characteristics of patients at start of trial. Values are medians (and $\stackrel{\text {. }}{*}$ confidence intervals

\begin{tabular}{|c|c|c|}
\hline & $\begin{array}{l}\text { Placebo group } \\
\quad(\mathbf{n}=30)\end{array}$ & $\begin{array}{l}\text { Sulphasalazine group } \\
\qquad(\mathrm{n}=30)\end{array}$ \\
\hline \multicolumn{3}{|c|}{ Demographic data } \\
\hline Age (years) & $37 \cdot 0(19 \cdot 0$ to $59 \cdot 0)$ & $38 \cdot 5(13 \cdot 1$ to $65 \cdot 3)$ \\
\hline $\operatorname{Sex}(\mathbf{M}: \mathbf{F})$ & $23: 7$ & $23: 7$ \\
\hline No with HLA B27 & 24 & 27 \\
\hline Duration of disease (years) & $10(-5 \cdot 0$ to $29 \cdot 2)$ & $10(-8 \cdot 8$ to $33 \cdot 2)$ \\
\hline \multicolumn{3}{|c|}{ Clinical variables } \\
\hline Score for daily dose of NSAIDs & $8 \cdot 0(0 \cdot 6$ to $18 \cdot 6)$ & $10 \cdot 0(-3 \cdot 4$ to $25 \cdot 2)$ \\
\hline Pain (mm) & $49 \cdot 5(-7 \cdot 2$ to $106 \cdot 8)$ & $32 \cdot 5(-17 \cdot 9$ to $97 \cdot 3)$ \\
\hline Joint index & $3.5(-7.8$ to 18.8$)$ & $4 \cdot 0(-5 \cdot 9$ to $17 \cdot 7)$ \\
\hline No of nocturnal awakenings & $0(-1 \cdot 2$ to $2 \cdot 4)$ & $0(-1.9$ to 3.1$)$ \\
\hline Functional index & $12 \cdot 5(-2 \cdot 1$ to $26 \cdot 9)$ & $13 \cdot 5(-4 \cdot 3$ to $30 \cdot 5)$ \\
\hline Schober's test & $4 \cdot 0(1 \cdot 3$ to $6 \cdot 3)$ & $3.5(0.2$ to 6.8$)$ \\
\hline Hand-ground distance $(\mathrm{cm})$ & $10 \cdot 0(-14 \cdot 5$ to $39 \cdot 3)$ & $20 \cdot 5(-20 \cdot 6$ to $46 \cdot 8)$ \\
\hline Chest expansion $(\mathrm{cm})$ & $17 \cdot 8(6 \cdot 8$ to $28 \cdot 0)$ & $17 \cdot 0(4 \cdot 6$ to $29 \cdot 8)$ \\
\hline \multicolumn{3}{|c|}{ Laboratory variables } \\
\hline $\begin{array}{l}\text { Erythrocyte sedimentation rate } \\
(\mathrm{mm} \text { in lst } \mathrm{h})\end{array}$ & $11 \cdot 0(-30 \cdot 7$ to $79 \cdot 9)$ & $13 \cdot 5(-17 \cdot 3$ to $54 \cdot 7)$ \\
\hline Haemoglobin $(g / 1)$ & 141 (109 to 179$)$ & $145(109$ to 178$)$ \\
\hline Platelet count $\left(\times 10^{9} / 1\right)$ & $332(147$ to 551$)$ & $346(113$ to 631$)$ \\
\hline $\operatorname{IgG}(\mathrm{g} / \mathrm{l})$ & $12 \cdot 8(2 \cdot 4$ to $24 \cdot 4)$ & $13.9(4.9$ to 24.5$)$ \\
\hline $\operatorname{IgA}(\mathrm{g} / \mathrm{l})$ & $2 \cdot 6(-0.3$ to 6.7$)$ & $2 \cdot 6(0.2$ to $5 \cdot 6)$ \\
\hline $\operatorname{IgM}(\mathrm{g} / \mathrm{l})$ & $1 \cdot 3(-0.2$ to 3.4$)$ & $1 \cdot 6(0 \cdot 3$ to $3 \cdot 1)$ \\
\hline
\end{tabular}

NSAIDs $=$ Non-steroidal anti-inflammatory drugs

TABLE II-Numbers of patients dropping out of trial for various reasons

\begin{tabular}{|c|c|c|}
\hline & Placebo group & Sulphasalazine group \\
\hline Inefficacy & 3 & 2 \\
\hline Side effects & 3 & 5 \\
\hline Nausea & & 3 \\
\hline Epigastric pain & 1 & \\
\hline Rash & 1 & \\
\hline Increased serum aspartate transaminase & & 1 \\
\hline Anaemia & 1 & \\
\hline Abdominal pain & & 1 \\
\hline Total & 6 & 7 \\
\hline
\end{tabular}

TABLE III-Numbers of patients who considered at end of trial that treatment had been a success or failure (figures in parentheses are numbers of patients who dropped out of trial)

\begin{tabular}{lcc}
\hline & Placebo group & Sulphasalazine group \\
\hline Success & 6 & 15 \\
Failure & $24(6)$ & $15(7)$
\end{tabular}

Latency of onset of activity of sulphasalazine - The latent period of the onset $\stackrel{\oplus}{+}$ of the activity of sulphasalazine was estimated by detailed analysis of changes $\square$ over time of some of the clinical and laboratory variables (figure). These allo showed that the two groups became distinct only from the third month of treatment. At this time statistical analysis with the Wilcoxon test showed in $\frac{\widehat{Q}}{\mathbb{D}}$ the group given sulphasalazine a reduction in the articular index (confidence $\varrho$ interval -8.4 to $5.4 ; \mathrm{p}<0.025)$; functional index $(-16.8$ to $7 \cdot 6 ; \mathrm{p}<0.005)$, Schober's test $(-2 \cdot 3$ to $1.3 \mathrm{~cm} ; \mathrm{p}<0.01)$; hand-ground distance $(-20.38$ to $13.1 \mathrm{~cm} ; \mathrm{p}<0.025)$; score for daily dosage of non-steroidal anti-o inflammatory drugs $(-18.7$ to $9.9 ; \mathrm{p}<0.005)$; erythrocyte sedimentation rate $(-30.5$ to $18.1 \mathrm{~mm}$ in $1 \mathrm{st} h ; \mathrm{p}<0.01) ; \operatorname{IgG}(-9.4$ to $7.6 \mathrm{~g} / \mathrm{l} ; \mathrm{p}<0.05) ; \operatorname{IgA}$ 을 
$(-2.5$ to $1.5 \mathrm{~g} / \mathrm{l} ; \mathrm{p}<0.025) ;$ and $\operatorname{IgM}(-1.2$ to $0.8 \mathrm{~g} / \mathrm{l} ; \mathrm{p}<0.025)$. The same analysis in the group given placebo showed a reduction in only the functional index $(-8.8$ to $6.0 ; \mathrm{p}<0.05)$; score for daily dosage of non-steroidal anti-inflammatory drugs $(-14 \cdot 3$ to $8 \cdot 1 ; \mathrm{p}<0.005)$, and erythrocyte sedimentation rate $(-33.1$ to $24.9 \mathrm{~mm}$ in $1 \mathrm{st} \mathrm{h} ; \mathrm{p}<0.05)$ and an improvement in chest expansion $(-4.1$ to $8.5 \mathrm{~cm} ; \mathrm{p}<0.01)$. The multiple comparisons performed, however, precluded any definitive conclusion.
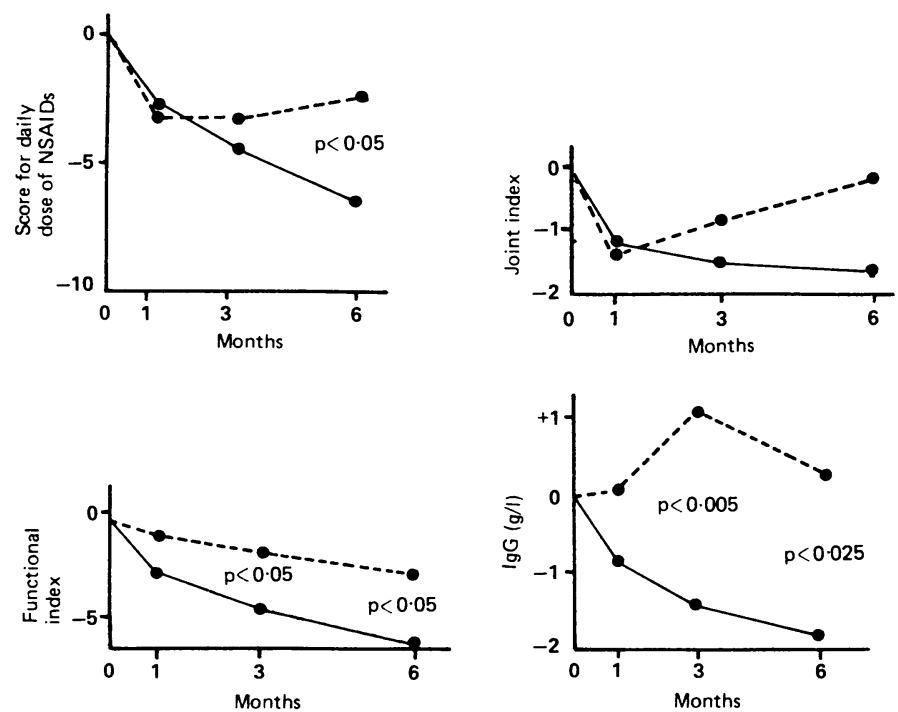

Change over time of certain clinical and laboratory variables in the group given placebo (--) and the group given sulphasalazine $(-)$. Values are means. Significance measured with Mann-Whitney U test. NSAIDs=Non-steroidal anti-inflammatory drugs.

Assessment of acceptability of treatment-Eight patients (three taking placebo and five taking sulphasalazine) had to stop treatment because of side effects (table II). In the group taking sulphasalazine four of these five withdrawals were due to digestive disturbances (nausea and abdominal pain); none was due to a rash. The patient in whom sulphasalazine was stopped because of a moderate ( 1.5 times the limit of normal) rise in plasma transaminase activity had shown a similar transient laboratory abnormality one year before the trial. The abnormality regressed one month after sulphasalazine was stopped but recurred six months later, when the patient was taking only piroxicam. Hepatitis B surface antigen was absent, and there was no other laboratory abnormality. Hepatitis induced by non-steroidal anti-inflammatory drugs was suggested, but the patient refused liver biopsy. Other clinical side effects occurred but were always minimal, transient, and, above all, equally common in both groups; they comprised gastric discomfort (one case), abdominal heaviness (one), tremor (one), and pruritus (one) in the group given placebo and anorexia (one), drowsiness (two), and pruritus (one) in the group given sulphasalazine. There were no cases of anaemia in the group given sulphasalazine. By contrast, mean corpuscular volume remained stable at $88 \mathrm{fl}$ in the group given placebo but increased from 86 to $91 \mathrm{fl}$ at the end of the trial in the group given sulphasalazine $(\mathrm{p}<0.001)$.

\section{Discussion}

Our results suggest that sulphasalazine may be an effective treatment in axial forms of ankylosing spondylitis and agree with the results of a recent study. ${ }^{9}$ Several remarks must nevertheless be made both about the patients and about the interpretation of the results.

Firstly, patients known to have inflammatory enterocolonic disease were deliberately excluded from the trial, but this criterion was based solely on the absence of symptoms suggestive of disease of the digestive tract. We worked in the conditions of everyday rheumatological practice; had exhaustive gastrointestinal investigations been undertaken we might have found evidence of asymptomatic microscopic Crohn's disease ${ }^{10}$ as well as macroscopic and microscopic inflammatory lesions of the ileocolonic mucosa. ${ }^{67}$

Secondly, although criteria are well established for selecting patients with rheumatoid arthritis to be included in a therapeutic trial of a slow acting drug, ${ }^{11}$ this is not true of ankylosing spondylitis The fluctuating nature of the course of this disease is well known, as is the fact that the disease is often considerably relieved by nonsteroidal anti-inflammatory drugs. We therefore decided to include only those patients requiring daily use of non-steroidal antiinflammatory drugs and to use a placebo controlled technique. Spontaneous fluctuations in the course of the disease probably explain the high proportion of patients given placebo whose condition improved and the wide individual variations, which are reflected by the wide confidence intervals (table IV); this justifies the controlled technique used for this trial.

TABLE IV-Change in each variable between start and end of trial in each group Values are medians (and confidence intervals)

\begin{tabular}{|c|c|c|}
\hline & $\begin{array}{l}\text { Placebo group } \\
\qquad(\mathrm{n}=24)\end{array}$ & $\begin{array}{l}\text { Sulphasalazine group } \\
\qquad(n=23)\end{array}$ \\
\hline \multicolumn{3}{|c|}{ Clinical variables } \\
\hline $\begin{array}{l}\text { Score for daily dose of NSAIDs } \\
\text { Pain (mm) } \\
\text { Joint index } \\
\text { No of nocturnal awakenings } \\
\text { Functional index } \\
\text { Schober's test } \\
\text { Hand-ground distance }(\mathrm{cm}) \\
\text { Chest expansion }(\mathrm{cm})\end{array}$ & $\begin{array}{l}-2 \cdot 9(-14 \cdot 9 \text { to } 10 \cdot 1)^{\star} \\
-6 \cdot 5(-84 \cdot 7 \text { to } 58 \cdot 9) \\
0(-10 \cdot 0 \text { to } 9 \cdot 4) \\
0(-4 \cdot 0 \text { to } 5 \cdot 0) \\
-2 \cdot 3(-13 \cdot 1 \text { to } 9 \cdot 3)^{\star} \\
0 \cdot 5(-1 \cdot 7 \text { to } 2 \cdot 5) \\
0(-14 \cdot 2 \text { to } 16 \cdot 2) \\
1 \cdot 0(-5 \cdot 3 \text { to } 9 \cdot 7)+t\end{array}$ & $\begin{array}{l}-6 \cdot 7(-20 \cdot 7 \text { to } 7 \cdot 7) \mathrm{tttt} \\
-9 \cdot 0(-62 \cdot 2 \text { to } 32 \cdot 8) \mathrm{tttt} \\
-1 \cdot 0(-8 \cdot 3 \text { to } 5 \cdot 1) \mathrm{t} \\
0(-2 \cdot 3 \text { to } 2 \cdot 5) \\
-4 \cdot 0(-18 \cdot 9 \text { to } 7 \cdot 1) \mathrm{tttt} \\
0 \cdot 5(-1 \cdot 7 \text { to } 2 \cdot 5) \\
-3 \cdot 0(-26 \cdot 0 \text { to } 18 \cdot 8) \mathrm{ttt} \\
1 \cdot 0(-5 \cdot 7 \text { to } 8 \cdot 3)\end{array}$ \\
\hline $\begin{array}{l}\text { Erythrocyte sedimentation rate } \\
\quad(\mathrm{mm} \text { in } 1 \mathrm{st} \mathrm{h}) \\
\text { Haemoglobin }(\mathrm{g} / \mathrm{l}) \\
\text { Platelet count }\left(\times 10^{9} / \mathrm{l}\right) \\
\mathrm{IgG}(\mathrm{g} / \mathrm{l}) \\
\mathrm{IgA}(\mathrm{g} / \mathrm{l}) \\
\mathrm{IgM}(\mathrm{g} / \mathrm{l})\end{array}$ & $\begin{array}{l}\text { Laboratory variables } \\
\begin{array}{l}-2 \cdot 0(-40 \cdot 8 \text { to } 25 \cdot 2) \dagger \\
3(-13 \text { to } 15) \\
-5 \cdot 0(-107 \cdot 7 \text { to } 88 \cdot 5) \\
0(-4 \cdot 9 \text { to } 6 \cdot 5)^{\star \star} \\
0 \cdot 1(-2 \cdot 9 \text { to } 3 \cdot 1) \\
0(-0.9 \text { to } 1 \cdot 3)\end{array}\end{array}$ & $\begin{array}{l}-2 \cdot 0(-32.5 \text { to } 14.5) \mathrm{tt+t} \\
0(-14 \text { to } 12) \\
-14.0(-54.7 \text { to }-16 \cdot 7) \\
-0.9(-5.3 \text { to } 8 \cdot 9) \mathrm{tt} \\
-0.3(-2 \cdot 1 \text { to } 1 \cdot 5) \\
-0.3(-1.0 \text { to } 0.4) \mathrm{tt+}\end{array}$ \\
\hline
\end{tabular}

NSAIDs $=$ Non-steroidal anti-inflammatory drugs.

Mann-Whitney U test: ${ }^{\star} p<0.05,{ }^{\star \star} \mathrm{p}<0.025$.

Wilcoxon's test: $t p<0.05, t+p<0.025, t+t p<0.01, t+t+p<0.005$

Detailed analysis of changes in the variables measured showed that the efficacy of sulphasalazine became apparent only from the third month of treatment, suggesting that it is not the salicylate compound of the molecule that is responsible. By analogy with the treatment of rheumatoid arthritis, it thus seems that sulphasalazine behaves not as a symptomatic treatment but as a slow acting agent. Furthermore, metabolic studies have clearly shown that sulphasalazine is poorly absorbed (less than 12\%), that in the colon sulphasalazine is split into sulphapyridine and 5 -aminosalicylic acid, and that all the sulphapyridine, but only $25 \%$ of the 5 -aminosalicylic acid, is absorbed. ${ }^{12}$ These metabolic data and the decrease in class A secretory Ig favour a local action on the digestive tract. This might be of an antimicrobial type, which, according to the theory of Ebringer, would prevent microbial infections causing acute exacerbations of the disease. ${ }^{13}$ Alternatively, it might be of an anti-inflammatory nature, treating macroscopic and microscopic abnormalities of the ileocolonic mucosa ${ }^{67}$; such abnormalities have been incriminated in the pathogenesis of spondyloarthropathies. ${ }^{7}$ These are hypotheses, particularly as a decrease in IgA and IgG during treatment with sulphasalazine has already been reported in patients with rheumatoid arthritis..$^{14} 15$

In the present trial the acceptability of the drug was good. The low proportion of patients in whom the drug had to be stopped because of digestive symptoms is probably attributable to the pharmaceutical form used. We used coated tablets of sulphasalazine; these have become available in France only recently and are better tolerated in the intestine than the non-coated form. Moreover, in this study the dose was not increased gradually. This method of administration might be useful to minimise side effects still further. No rashes or megaloblastic anaemia occurred. ${ }^{16-18}$ This trial confirmed that corpuscular volume increases with treatment, this abnormality being believed to be secondary to minimal haemolysis. ${ }^{19}$ 
Longer term studies are necessary to determine whether treatment with sulphasalazine can prevent late complications such as ankylosis and whether it can induce prolonged remissions of the disease.

\section{References}

1 Peppercorn MA. Sulfasalazine: pharmacology, clinical use, toxicity and related new drug development. Ann Intern Med 1984;3:377-86.

2 McConley B, Amos RS, Durham S, Forster PJC, Hitball S, Walsh L. Sulphasalazine in rheumatoid arthritis. BrMed f 1980;280:442-4.

3 Pullar T, Capell H. Sulphasalazine: a "new" antirheumatic drug. Br $\mathcal{f}$ Rheumatol 1984;23:26-8.

4 Amor B, Kahan A, Dougados M, Delrieu F. Sulfasalazine and ankylosing spondylitis. Ann Intern Med 1984;101:878.

5 Ebringer RW, Cawdell DR, Cowling P, Ebringer A. Sequential studies in ankylosing spondylitis. Association of Klebsiella pneumoniae with active disease. Ann Rheum Dis 1979;37:146-51.

6 Alemanni $M$, Dougados $M$, Abadia $R$, et al. Ileocolonoscopy and bowel histology in patients with seronegative spondyloarthropathies. European League Against Rheumatism Symposium (in press).

Mielants R, Veys EM. Inflammation of the ileum in patients with $B 27$ positive reactive arthritis. Lancet 1984; iv: 288 .

8 Bennett PH, Burch TA. New York symposium on population studies in the rheumatic diseases: new diagnostic criteria. In: Rodnan GF, ed. Bulletin on the rheumatic diseases. New York: Arthritis Foundation, 1967:453-8.

9 Feltelius N, Hallgren R. Sul:4salazine in ankylosing spondylitis. Ann Rheum Dis 1986;45:396-9.

10 Surawiz CM Meisel JL, Ylvisaker T, Saunders DR Rubin CE. Rectal biopsy in the diagnosis of Crohn's disease: value of multiple biopsies and serial sectioning. Gastroenterology 1981;80: $66-72$.

11 European League Against Rheumatism. Guidelines for the clinical investigation of drugs used in rheumatic diseases. Copenhagen: World Health Organisation, 1985:7-11

12 Azadkhan AK, Truelove SC, Aronson JK. The disposition and metabolism of sulphasalazine (salicylazosulphapyridine) in man. Br f Clin Pharmacol 1982;13:523-8.

13 Ebringer A. The cross tolerance hypothesis, HLA B27 and ankylosing spondylitis. Br $\mathcal{F}$ Rheumatol 1983;22(suppl 2):53-66.

14 Delamere JP, Farr M, Grindulis KA. Sulphasalazine induced selective IgA deficiency in rheumatoid arthritis. Br Med f 1983;286:1547-8.

15 Savilahti E. Sulphasalazine induced immunodeficiency. Br Med f 1983;287:759.

16 Bax DE, Amos RS. Sulphasalazine in rheumatoid arthritis: desensitising the patient with a skin rash. Ann Rheum Dis 1986; 45:139-40.

17 Mielsen $\mathrm{OH}$. Sulfasalazine intolerance: a retrospective survey of the reasons for discontinuing treatment with sulfasalazine in patients with chronic inflammatory disease. Scand $\mathcal{f}$ Gastroenterol 1982;17:389-93.

18 Schneider R, Beeley L. Megaloblastic anaemia associated with sulphasalazine treatment. Br Med f $1977 ; i: 1638$.

19 Grindulis KA, McConley B. Does sulphasalazine cause folate deficiency in rheumatoid arthritis? Scand f Rheumatol 1985;14:265-70.

(Accepted 16 fuly 1986)

\title{
Contribution of inappropriate treatment for hypertension to pathogenesis of stroke in the elderly
}

\author{
P A F JANSEN, F W J GRIBNAU, B P M SCHULTE, E F J POELS
}

\begin{abstract}
One hundred and seventy eight patients admitted to hospital with acute cerebral infarction or transient ischaemic attack were studied to determine if their treatment had been changed during the previous three weeks and to compare their blood pressure after the stroke with premorbid values. Blood pressure measurements taken within one year before the stroke were available for 100 patients; seven of these had had a recent change in antihypertensive or diuretic treatment. Of these, three patients who had started taking frusemide because of hypertension and one whose dosage of a reserpine combination drug had been increased experienced an appreciable decrease in blood pressure immediately after the stroke; they also showed signs of haemoconcentration. The change in treatment probably contributed to the stroke in these four patients. The other three showed a smaller decrease or even an increase in blood pressure and no signs of haemoconcentration; the relation between the change in treatment and stroke is less likely in these patients.

The use of high ceiling diuretics such as frusemide in the treatment of hypertension may induce hypovolaemia and hypotension, resulting in cerebral ischaemia, and are therefore best avoided in such treatment.
\end{abstract}

\footnotetext{
Division of General Internal Medicine, Department of Medicine and Division of Clinical Pharmacology and Pharmacokinetics, Laboratory of Pharmacology, and Institute of Neurology, Catholic University of Nijmegen, PO Box 9101, 6500 HB Nijmegen, The Netherlands

P A F JANSEN, MD, internist

F W J GRIBNAU, MD, professor of clinical pharmacology

B P M SCHULTE, MD, professor of neurology
}

Department of Neurology, Canisius-Wilhelmina Hospital, Nijmegen, The Netherlands

E F J POELS, MD, neurologist

Correspondence to: Dr Jansen.

\section{Introduction}

Increased blood pressure, especially systolic hypertension, is associated with an increased risk of stroke in people aged over $60 .^{1.5}$ Other studies, including one by the European Working Party on High Blood Pressure in the Elderly, have shown that treatment for hypertension in the elderly reduces cardiovascular and cerebrovascular mortality and morbidity, ${ }^{6-9}$ particularly non-fatal cerebrovascular events. ${ }^{6}$ Treatment for hypertension may prevent the recurrence of stroke, ${ }^{10}{ }^{11}$ especially cerebral haemorrhage,${ }^{12}$ but this effect in the elderly is less certain. ${ }^{13}{ }^{14}$ Nevertheless, treatment for hypertension in the elderly should be considered, though there is no consensus about the diastolic or systolic pressure above which treatment should be given.

Stroke as a paradoxical side effect of treatment for hypertension has been reported. ${ }^{1522} \mathrm{We}$ previously sent a questionnaire to all medical directors of Dutch nursing homes $(n=322)$ asking for information on patients who suffered a stroke shortly after the start of antihypertensive or diuretic treatment. Thirty patients were reported $^{23}$; complete blood pressure measurements were available for nine of them. They had all had an appreciable decrease in blood pressure immediately after the stroke. To establish whether inappropriate antihypertensive or excessively drastic diuretic treatment causes such events, and if so how often, we studied patients admitted to hospital with transient ischaemic attack or acute cerebral infarction to determine if there had been any change in treatment during the three weeks preceding admission and to measure blood pressure immediately after the event and compare it with premorbid values.

\section{Patients and methods}

We studied 178 consecutive patients with cerebral infarction or transient ischaemic attack admitted to the neurology department of a community hospital. In the emergency department a medical history was taken, including drugs being taken, and a standard physical and neurological examination was performed. Blood pressure was measured with a sphygmomanometer, and an electrocardiogram was recorded. Blood was collected for 